\title{
Characteristics and management of patients with hemophagocytic lymphohistiocytosis masquerading as liver failure
}

\author{
Yahong You \\ Capital Medical University \\ Jingshi Wang \\ Capital Medical University
}

Zhao Wang ( $\triangle$ wangzhao@ccmu.edu.cn )

Capital Medical University

\section{Research Article}

Keywords: Liver, failure, hemophagocytic lymphohistiocytosis, treatment.

Posted Date: April 26th, 2021

DOI: https://doi.org/10.21203/rs.3.rs-443103/v1

License: (c) (i) This work is licensed under a Creative Commons Attribution 4.0 International License. Read Full License 


\section{Abstract}

Liver failure (LF) is a lethal condition characterized by jaundice, coagulation disorders. patients with LF carry a high mortality. Hemophagocytic lymphohistiocytosis (HLH) is established as a rare cause of LF. However, the clinical course of HLH may not be familiar to most hepatologist. We aimed to decipher the characteristics of these patients, to provide experience in the diagnose and management of patients with HLH masquerading as LF. Nine patients initially diagnosed with LF and finally developed HLH between January 2017 and October 2020 were retrospectively included. 78\% cases developed LF with no discernable causes. Unexplained cytopenia and recurrent fever with LF may be a red flag for suspicion of HLH. Besides, female maybe predispositional to HLH in the context of LF. Modified DEP regimen was effective to control the fatal inflammatory state, all 9 cases achieved response after only one course. Further, three courses of treatment could substantially make the blood count and liver function return to normalcy, and without recurrence of $\mathrm{HLH}$.

\section{Introduction}

Liver failure (LF) is heterogeneous in etiology and prognosis, it is a life-threatening syndrome, in which rapid deterioration of liver function results in deep jaundice, altered mentation and coagulopathy [1]. The most prominent causes include hepatotoxic drug, viral infection, immune-mediated attack, and hypoperfusion, about one-third of patient even has no discernible cause [1-3]. Albeit rare, a well-established etiology for LF is hemophagocytic lymphohistiocytosis $(\mathrm{HLH})$, thus, a patient may masquerade as LF in the clinical course of HLH [4-6]. Patients may be admitted in a center of hepatology or an intensive care unit for the complaining of deep jaundice and fatigue. Unfortunately, HLH may not be familiar to most physician, therefore, diagnosis of $\mathrm{HLH}$ in the context of LF is exceptionally challenging.

HLH has no significant racial or sexual predilection, it is a multisystemic clinicopathologic syndrome characterized by aberrantly activated cytotoxic $T$ cells and macrophages, with resultant hyperinflammation and hypercytokinemia [7]. Clinically, prolonged fever, splenomegaly, cytopenias, hyperferritinemia and hemophagocytosis evidence are the prominent signs of HLH. Although not included in the accepted HLH-04 diagnostic criteria, evidence of liver dysfunction can be found in over $80 \%$ patients, ranging from slight elevation of transaminases to LF, thus, LF can be a manifestation of $\mathrm{HLH}$ at a certain stage of its development [8-9]. Traditionally, HLH is classified into primary and secondary forms, LF can be the prominent sign of both forms. Underlying genetic defects play a pivotal role in the onset of primary form, secondary HLH are subclassified as infection, autoimmune, or neoplasia related, some cases are still fulfilled HLH even with unknown cause [9-10]. Currently, standard HLH-94, HLH-04 and the salvage DEP regimen have made a remarkable progress in treatment of HLH [11-12]. However, no unanimous therapy has been reached on the treatment of patients with HLH in the context of LF.

As far as the patient management is concerned, it would be a great challenge for gastroenterologists and hepatologists. The reported data showed that patients with LF and HLH have dismal outcome with liverprotective treatment, plasma exchange, glucocorticoids and gamma globulin [5, 13-14]. Liver transplantation may be considered as a curative treatment for LF, however, some researches revealed that HLH is regarded as a controversial indication for liver transplantation considering the systematic nature and risk of 
posttransplant recurrence [13-15]. Even though, very expensive cost would be devoted to the treatment of LF and $\mathrm{HLH}$, the results were disappointing.

Based on the current situation, it is self-evident that an optimal therapy beneficial to manage the disease is in urgently need. Studies on HLH in the context of LF are mostly available as case reports. Herein, we carried out a retrospective study to decipher the clinical and laboratory feature of HLH masquerading as LF, aimed to provide key clues for early diagnosis. We also introduce our experience in managing this fatal disease: LF and $\mathrm{HLH}$.

\section{Materials And Methods}

\section{Subjects and objectives}

We conducted a retrospective cross-sectional study of patients who were newly diagnosed with LF and HLH at one single institution (Beijing Friendship Hospital, Capital Medical University) between January 2017 and October 2020. Informed consent was obtained from all patients or their guardians, agreed to participate in this study. Appropriate ethical approval was approved by Beijing Friendship Hospital Affiliated Capital Medical University in accordance of the Declaration of Helsinki.

In all, 9 patients were referred as cases with imminent or confirmed LF and were admitted to the hepatic diseases center for treatment. In the early stages of the disease, they were diagnosed with LF but not meet the criteria of HLH. In the clinical course, recurrent fever, cytopenia, and other signs of HLH were gradually appeared, they were finally diagnosed with $\mathrm{HLH}$ and presented to our center as a hospital transfer for further management of HLH in the context of LF. Data were retrieved including etiological screening, clinical and laboratory features, medical history, HLH genetic testing, treatment, and outcomes.

\section{Diagnosis and definition}

The diagnosis of LF had been made according to the 2018 Chinese guideline criteria for diagnosis and treatment of liver failure [2]. The diagnosis of HLH was established in accordance with the internationally accepted guideline of HLH-2004 [16], and the diagnosis was stringently enforced, meeting five out of eight criteria was a necessity.

The efficacy was evaluated at days 14 after initiated every course of modified DEP regimen. Response to therapy was defined as complete response (CR), partial response (PR), and no response (NR) [12]. CR was defined as normalization of clinical symptoms and laboratory parameters of $\mathrm{HLH}$, including levels of SCD25, ferritin, and triglyceride (TG), fibrinogen, hemoglobin (HGB), white blood cell count (WBC), platelet counts (PLT), alanine aminotransferase (ALT), aspartate aminotransferase (AST), total bilirubin (TBIL), and direct bilirubin (DBIL). PR was defined as at least a $50 \%$ improvement in two or more laboratory markers. NR was defined as failing to achieve PR.

\section{Treatment of HLH}


Modified DEP regimen was as follows (Figure1): liposomal doxorubicin15-25 mg/m2 d1; Etoposide 100 $\mathrm{mg} / \mathrm{m} 2 \mathrm{~d} 1$, methylprednisolone 1-1.5mg/kg d1-5, 0.3-0.6mg/kg d6-14. This two-week regiment will be repeated for 4 courses continuously. The efficacy was evaluated at days 14 after initiating each modified DEP therapy. After 4 courses, methylprednisolone will be tapered gradually. Ruxolitinib was also added when the full-dose glucocorticoid was intolerable, the dose was $0.3 \mathrm{mg} / \mathrm{kg} /$ day.

\section{Statistical analysis}

Descriptive data is described by median and range, with minimum and maximum values for continuous variables. Categorical statistics are present as number and percentage (\%). For intergroup comparison of data, a Mann-Whitney U test and a Wilcoxon rank-sum test were performed. Paired-sample $T$ test was used to compare the changes between groups where suitable. Difference was considered to be significant if the $P$ value was less than 0.05. All the analyses were conducted using SPSS 21.0 (SPSS, Chicago, IL).

\section{Results}

\section{Characteristics of the patients with LF}

As table 1 displayed, 9 cases with provisional diagnosis of LF were referred from hepatic diseases hospital. Fever was the first prominent signs of most patients, then progressive jaundice and fatigue appeared, 7 patients were diagnosed with acute LF, and the rest 2 cases were subacute LF. The workup for viral hepatitis (IgM-HAV, HBV-DNA, Anti-HCV and IgM-HEV) was negative. Tests for antinuclear antibody spectrum, extractable nuclear antibody spectrum, and anti-neutrophil cytoplasmic antibodies were negative. Antimitochondrial antibody was negative and serum ceruloplasmin level was normal. They were all non-drinkers and had no history of liver disease previously. Possible etiology for LF was drug-induced (2 cases), and 7 cases with no discernable causes. Liver-protective treatment together with plasma exchange and glucocorticoid were the main strategies. However, the effect was unsatisfying, pancytopenia and recurrent fever began to be the most pronounced manifestation. Extensive workup was done to evaluate the situation, and then, the signs of hemophagocytosis and elevated ferritin and hypertriglyceridemia were predisposed to the diagnosis of $\mathrm{HLH}$.

\section{Features of HLH in the context of LF}

The features of patients were depicted in table 2. The mean time from prodromal to a certain diagnosis of LF was 49.6 days (range, 6-210 days). The average interval from LF to HLH was 22 days (range, 9-50 days). The average time from the first sign of disease to a certain diagnosis of HLH was 71.6 days (range, 20-230 days). Patients were admitted with a median age of 37 years (range: 15-64 years), including 8 females and 1 male (11\%), an obvious gender difference was observed.

The laboratory findings of patients at different stage of the disease (provisional diagnosis of LF vs. HLH) were dramatically changed, complete blood count was deeply declined: WBC (7.7 \pm 3.4 vs. 4.1 $\pm 4.5, P=0.038)$, HGB (119.0 \pm 20.1 vs. $80.4 \pm 21.9, P=0.008)$, PLT (158.7 \pm 86.9 vs. $49.8 \pm 28.7, P=0.008)$. However, compared with the LF stage, when patients were finally diagnosed with $\mathrm{HLH}$, liver aminotransferase showed some

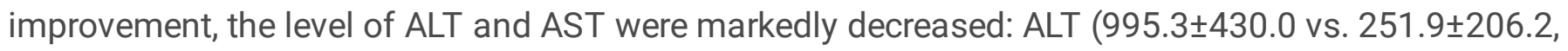


$\mathrm{P}=0.008)$, AST (957.8 \pm 653.5 vs. $366.9 \pm 401.7, \mathrm{P}=0.038)$. Intriguingly, the bilirubin were continuously elevated at the stage of HLH diagnosis: TBIL ( $315.8 \pm 113.1$ vs. $414.4 \pm 244.6, P=0.214)$, DBIL (206.5 \pm 90.1 vs.

$255.4 \pm 180.7, P=0.515)$. This phenomenon indicated that unexplained cytopenia and recurrent fever may be a red flag of suspicion of $\mathrm{HLH}$.

All cases present with persistent high-grade fever, $88.9 \%$ encountered splenomegaly and hemophagocytosis. Four cases showed pancytopenia, and 4 cases have bicytopenia. Most cases have elevated ferritin over $500 \mathrm{ng} / \mathrm{mL}$ (8 in 9 cases, 88.9\%), elevated soluble IL-2 receptor (sCD25, >6400pg/mL) were detected in all cases. Decrease nature killer cell activity occurred in $66.7 \%$ patients. Besides, hypofibrinogenemia $(<1.5 \mathrm{~g} / \mathrm{L})$ accounting for $88.9 \%$ cases and hypertriglyceridemia $(>3.0 \mathrm{mmol} / \mathrm{L})$ was observed in 7 out of all 9 cases.

\section{Etiology of HLH in the context of LF}

All patients were extensively evaluated for persistent febrile illness for dengue, malaria, rickettsia, leptospirosis, human immunodeficiency virus and brucella along with blood and urine cultures, which were inconclusive. Herpes virus DNA (epstein-barr virus, cytomegalovirus, herpes simplex viruses, varicella zoster, human herpesvirus 6, human herpesvirus 7, human herpesvirus 8) were all negative. A full-body CT or F-18 fluoro-2-deoxyglucose positron emission tomography/computed tomography scan for malignant tumors (especially lymphoma) was inconclusive. All cases were in absence of HLH family history, genetic test (PRF1, STX11, and UNC13D) were negative, besides, the related protein (perforin, munc 13-4, granzyme B, CD107a, $\mathrm{X}$-linked inhibitor of apoptosis protein, signaling lymphocytic activation molecule associated protein were roughly normal. Evidence of infection, autoimmune disease and neoplasms were extensively examined. After extensively workup for HLH, one patient was considered as HLH secondary to adult- onset still's disease, other cases were secondary HLH with unknown causes.

\section{Treatment with modified DEP regimen, side effects and complications}

All 9 cases in our cohort present with deep jaundice and recurrent fever, most patients underwent a period of time of glucocorticoid treatment before admission. Once diagnosed, HLH-directed treatment was initiated. In all, 6 patients received 4 courses of modified DEP regimen, 3 patients (P1, P5, and P8) underwent prescribed 4 courses of modified DEP regimen. One patient $(\mathrm{P} 2)$ received one course of full-dose prescribed therapy, then bradycardia occurred, liposomal doxorubicin was withdrawn from the remaining 3 courses. Two cases (P4 and P9) have lower gastrointestinal bleeding after one cycle, appropriately supportive therapies were given, including platelet or clotting factor infusion. The use of glucocorticoid was contraindicated by bleeding, ruxolitinib was added in the remaining 3 courses. The other 3 cases had not completed the whole treating course: 1 case (P3) underwent 2 treatment, her liver test was nearly recovered, she felt well and had no further treatment, 1 patient (P6) received 2 courses of treatment, and then, she had radiological signs of pulmonary, infection was improved after antibiotic treatment, but she did not continue the therapy for economy causes, the patient died of sepsis. A patient (P7) had severe acute pancreatitis and finally succumbed to a fatal for multiple organ failure after 2 courses.

\section{Response rate and changes in evaluation indicators after treatment}


A total of 9 patients were diagnosed with HLH in the context of LF, all patients were responsive to the modified DEP regimen, all of the cases achieved PR after 1 course. Of the 6 cases who received 4 courses of treatment, 5 cases achieved CR (83.3\%), one case revealed PR (16.7\%). In all, after several courses of modified DEP regimen, overall response rate was 100\%, 5 cases (55.6\%) achieved CR, and another 4 cases (44.4\%) got PR.

The parameters were evaluated at HLH diagnosis and at days 14 after initiating each course of modified DEP regimen. These evaluation indicators were concluded in table 3. PLT was the first index in blood count to improve. Biotransformation function of liver (ALT, AST, TBIL, DBIL and TG) was markedly improved once HLHdirected therapy was initiated, the index decreased a lot as compared with baseline of HLH diagnosis after only 1 course, these parameters tended to recover to normal after 3 courses (Figure 2). To a certain extent, the disorders of liver synthesis were also restored, with the level of fibrinogen and serum albumin dramatically elevated after 1 or 2 courses ( $P=0.038$ and $P=0.012$, respectively). The level of sCD25 was also sharply decreased after one course of therapy.

No case experienced HLH recurrence at a median of 14.8 months (range, 1.35-27.5 months) after treatment. Two patients died (overall survival rate 77.7\%), six patients were alive and well at a median of 16 months (range, 5.2-27.5 months).

\section{Discussion}

We reported a single center experience of 9 patients with HLH in the context of LF. HLH has a wide spectrum of clinical manifestations, however, LF as a presentation of $\mathrm{HLH}$ is a rare and serious condition with very high mortality and morbidity [4-6]. LF may dominated the clinical presentation in HLH patients at a certain early stage of the disease, patients usually received LF-directed therapy at a department of hepatology [6]. Our study was powered to decipher characteristics and management of this group of patients. The average time from the first sign of disease to a certain diagnosis of HLH was 71.6 days, therefore, awareness of HLH may be the most important to early diagnosis. Besides, according to the reports, women were predispositional to $\mathrm{HLH}$ in the context of LF and most cases had indeterminate cause for LF $[6,17]$. Our results were similar to the document, in our cohort, an obvious gender difference was observed, with 8 women and 1 man in all patients, thus female maybe predispositional to HLH patients in the context of LF. Besides, most patients with LF were also had no discernable causes. Therefore, in female patients with LF of indeterminate etiology, HLH should be suspected with a high degree, especially at the following conditions: unexplained progressively cytopenia, recurrent fever. A high index of suspicion is an indispensable condition for prompt diagnosis and fatal disease prevention. Additionally, hemophagocytosis in bone marrow and the increased level of sCD25 were indicators for HLH with high sensitivity.

HLH can occur simultaneously with LF, lag behind LF or develop during the treatment $[5-6,18]$. In our cohort, diagnosis of HLH lagged behind LF, the average interval from LF to HLH was 22 days. Complete blood count sharply decreased at HLH diagnosis compared to stage of LF, however, amelioration of liver function was also detected, with the level of ALT and AST dropped markedly. According to the report [6], TBIL is also decreased when HLH was diagnosed, however, it is worth noting that patients in our cohort had a tendency for increased bilirubin as with the progressing of LF to HLH. To date, reasons of liver injury in HLH remain 
unknown, potential mechanism were: hepatocyte necrosis, activated macrophages and T cell-predominant cellular infiltrate in the portal tracts, interferon-gamma pathway upregulation in the liver tissue and systemic inflammatory or immune-targeted injury $[13,19-20]$. All form of HLH can occur LF prior to HLH, the etiology of $\mathrm{HLH}$ were mostly inconclusive $[4,13]$. Etiology causes of $\mathrm{HLH}$ was extensively scrutinized, similar to the documented data, one patient was considered as HLH secondary to adult-onset still's disease, the remaining 8 cases were secondary HLH without conclusive underlying disease.

The in-hospital mortality rate was significantly higher in cases of secondary or primary HLH presenting with $\operatorname{LF}[6,21]$. At present, there is no unanimously recommended therapy on the management of coexistence of two clinical conditions: LF and HLH. Liver-protective treatment together with plasma exchange and glucocorticoid were the main strategies for LF, when HLH encountered, cyclosporine, intravenous immunoglobulin, etoposide or fludarabine were once attempted, however, about half patients succumbed to progression disease $[4-5,22]$. Though, case series studies reported that about $67 \%$ patients with LF and HLH stay alive after liver transplantation, however, over half of these alive cases experienced $\mathrm{HLH}$ recurrence [1314]. Thus, liver transplantation may be a potentially lifesaving intervention, but it would not resolve underlying problems. Additionally, considering donor source and huge cost, liver transplantation is difficult to implement for most patients in development countries.

DEP regimen was firstly described as a salvage treatment for relapse or refractory $\mathrm{HLH}$, however, complications such as bleeding, myelosuppression, and infection were also observed [12]. Etoposide electively depleted activated T cells leading to suppression of inflammatory cytokines, thus etoposide was regarded as the core HLH treatment [23]. It was regarded that the use of etoposide may be contraindicated by $L F$, however, out data showed that dose adjusted DEP regimen, etoposide, doxorubicin and methylprednisolone were well tolerated in the patients with HLH and LF. Response to therapy was evaluated by clinical and laboratory evidence of resolution. All patients achieved PR after just one course of modified DEP regimen, with improved index of biotransformation function and blood count, also with decreased SCD25 and ferritin. Three courses of treatment would enough to restore the function of liver and fully control the $\mathrm{HLH}$. It is intriguing that no case experienced $\mathrm{HLH}$ recurrence after treatment. Altogether, modified DEP regimen would be a potentially lifesaving intervention that allows for a cure of HLH in the context of LF.

Despite retrospective nature and limited sample size, our study depicted the clinical and laboratory features of HLH in the context of LF, the indicative information may provide clues for early diagnosis of HLH which masqueraded as LF. In relation to treatment, modified DEP regimen can effectively restore the liver function and cure HLH.

\section{Abbreviations}

LF, liver failure; $\mathrm{HLH}$, hemophagocytic lymphohistiocytosis; CR, complete response; PR, partial response; NR, no response; TG, triglyceride; HGB, hemoglobin; WBC, white blood cell count; PLT, platelet counts; ALT, alanine aminotransferase; AST, aspartate aminotransferase; TBIL, total bilirubin; DBIL, direct bilirubin

\section{Declarations}


The authors would like to thank all the doctors and nurses in the Department of Hematology in Beijing Friendship Hospital, Capital Medical University. We also thank the haematologists, radiation, laboratory, pathologists and all other participating department for the sustained scientific collaboration.

\section{Authorship Contributions}

Y.Y. contributed to the study design, data analysis and interpretation, and writing the report. J.W. and Z.W. contributed to patient registration and treatment, data collection, and writing and approval of the manuscript. All other authors contributed equally to data collection and review of the manuscript. No medical writer was involved in the study and the manuscript.

\section{Conflict of interest statement}

The authors declared that they have no commercial, proprietary, financial interest or any potential conflicts in the producers or companies described in this manuscript. All authors have submitted the ICMJE Form for Disclosure of Potential Conflicts of Interest. Besides, the information has never been presented in any meeting previously.

\section{Funding details}

This work was supported by grants from the National Natural Science Foundation of China (grant number: 81871633), the Beijing Natural Science Foundation (grant number: 7181003) and Beijing Municipal Administration of Hospital Incubating Program (Code: PX2018003).

Competing Interests: The authors declare no competing interests.

\section{References}

[1] Ostapowicz GA, Fontana RJ, Schiodt FV, et al. Results of a prospective study of acute liver failure at 17 tertiary care centers in the United States. Ann Intern Med 2002; 137:947-954.

[2] Liver Failure and Artificial Liver Group, Chinese Society of Infectious Diseases, Chinese Medical Association; Severe Liver Diseases and Artificial Liver Group, Chinese Society of Hepatology, Chinese Medical Association. Guidelines for diagnosis and treatment liver failure. Journal of Southwest Medical University 2019; 42(2):99-105

[3] Polson J, Lee WM. AASLD position paper: The management of acute liver failure. Hepatology, 2005, 41(5): 1179-1197.

[4] Nitin J, Mithun S, Gupta R, et al. Hemophagocytic lymphohistiocytosis masquerading as acute liver failure: a single center experience. J Clin Exp Hepatol 2017; 7(3):184-189.

[5] Dong J, Xie F, Jia L, et al. Clinical characteristics of liver failure with hemophagocytic lymphohistiocytosis. Sci Rep. 2019; 9(1):8125. 
[6] Ryu JM, Kim KM, Oh SH, et al. Differential clinical characteristics of acute liver failure caused by hemophagocytic lymphohistiocytosis in children. Pediatr Int. 2013; 55(6):748-52.

[7] La Rosée P, Horne A, Hines M, et al. Recommendations for the management of hemophagocytic lymphohistiocytosis in adults. Blood 2019; 133:2465-2477.

[8] Li J, Wang Q, Zheng W, et al. Hemophagocytic lymphohistiocytosis: clinical analysis of 103 adult patients. Medicine (Baltimore). 2014; 93(2):100-5.

[9] Ramos-Casals M, Brito-Zero' n P, Lo' pez-Guillermo A, Khamashta MA, Bosch X. Adult haemophagocytic syndrome. Lancet. 2014; 383:1503-1516.

[10] Madkaikar M, Shabrish S, Desai M. Current Updates on Classification, Diagnosis and Treatment of Hemophagocytic Lymphohistiocytosis (HLH). Indian J Pediatr. 2016; 83:434-43.

[11] Trottestam H, Horne A, Aricò M, et al. Chemoimmunotherapy for hemophagocytic lymphohistiocytosis: long-term results of the HLH-94 treatment protocol. Blood. 2011; 118: 4577-84.

[12] Wang $Y$, Huang $W, H u L$, et al. Multicenter study of combination DEP regimen as a salvage therapy for adult refractory hemophagocytic lymphohistiocytosis. Blood. 2015; 126: 2186-92.

[13] Amir AZ, Ling SC, Naqvi A, et al. Liver transplantation for children with acute liver failure associated with secondary hemophagocytic lymphohistiocytosis. Liver Transpl. 2016; 22(9):1245-53.

[14] Ayvazoğlu Soy EH, Alam H, Olcay L, et al. Liver transplant in a patient with hemophagocytic lymphohistiocytosis. Exp Clin Transplant. 2019; 17(Suppl 1):226-229.

[15] Nusshag C, Morath C, Zeier M, et al. Hemophagocytic lymphohistiocytosis in an adult kidney transplant recipient successfully treated by plasmapheresis: A case report and review of the literature. Medicine (Baltimore). 2017; 96(50): e9283.

[16] Henter Jl, Horne A, Arico M, et al. HLH-2004: diagnostic and therapeutic guidelines for hemophagocytic lymphohistiocytosis. Pediatr Blood Cancer 2007; 48:124-131.

[17] Lin S, Li Y, Long J, et al. Acute liver failure caused by hemophagocytic lymphohistiocytosis in adults A case report and review of the literature. Medicine (Baltimore). 2016; 95(47): e5431.

[18] Li F, Yang Y, Jin F, et al. Clinical characteristics and prognostic factors of adult hemophagocytic syndrome patients: a retrospective study of increasing awareness of a disease from a single-center in China. Orphanet J Rare Dis. 2015 Feb 15(10):20.

[19] Prencipe G, Bracaglia C, Caiello I, et al. The interferon-gamma pathway is selectively up-regulated in the liver of patients with secondary hemophagocytic lymphohistiocytosis. PLoS One. 2019; 4(12): e0226043.

[20] Chen JH, Fleming MD, Pinkus GS, et al. Pathology of the liver in familial hemophagocytic lymphohistiocytosis. Am J Surg Pathol. 2010; 34: 852-867. 
[21] Ryu JM, Kim KM, Oh SH, et al. Differential clinical characteristics of acute liver failure caused by hemophagocytic lymphohistiocytosis in children. Pediatr Int. 2013; 55(6):748-52.

[22] Juan Li, Hongwei Yu, Haixia Liu, et al. Clinical analysis of 9 cases of liver failure with hemhphagocytic syndrome. Chin J Hepatol. 2015; 23 (7): 538-539.

[23] Johnson TS, Terrell CE, Millen SH, et al. Etoposide selectively ablates activated T cells to control the immunoregulatory disorder hemophagocytic lymphohistiocytosis. J Immunol, 2014; 192(1): 84-91.

\section{Tables}

Table 1. Characteristics of the patients at the diagnosis of liver failure

\begin{tabular}{|c|c|c|c|c|c|c|c|c|}
\hline Patient & Sex & $\mathrm{Age}$ & $\begin{array}{l}\text { Type of } \\
\text { LF }\end{array}$ & Etiology & $\begin{array}{l}\text { Prodromal } \\
\text { to LF }\end{array}$ & $\begin{array}{l}\text { Interval from LF } \\
\text { to HLH }\end{array}$ & $\begin{array}{l}\text { Underlying } \\
\text { disease }\end{array}$ & $\begin{array}{l}\text { Alcohol } \\
\text { intake }\end{array}$ \\
\hline $\begin{array}{l}1 \\
2 \\
3 \\
4 \\
5 \\
6 \\
7 \\
8 \\
9\end{array}$ & $\begin{array}{l}\mathrm{F} \\
\mathrm{M} \\
\mathrm{F} \\
\mathrm{F} \\
\mathrm{F} \\
\mathrm{F} \\
\mathrm{F} \\
\mathrm{F} \\
\mathrm{F}\end{array}$ & $\begin{array}{l}37 \\
15 \\
64 \\
25 \\
40 \\
43 \\
15 \\
24 \\
55\end{array}$ & $\begin{array}{l}\text { ALF } \\
\text { ALF } \\
\text { SALF } \\
\text { ALF } \\
\text { SALF } \\
\text { ALF } \\
\text { ALF } \\
\text { ALF } \\
\text { ALF }\end{array}$ & $\begin{array}{l}\mathrm{NF} \\
\mathrm{NF} \\
\text { Drug } \\
\mathrm{NF} \\
\mathrm{NF} \\
\text { Drug } \\
\mathrm{NF} \\
\mathrm{NF} \\
\mathrm{NF}\end{array}$ & $\begin{array}{l}68 \\
65 \\
210 \\
21 \\
47 \\
10 \\
14 \\
6 \\
32\end{array}$ & $\begin{array}{l}24 \\
20 \\
27 \\
24 \\
20 \\
50 \\
10 \\
14 \\
9\end{array}$ & $\begin{array}{l}\mathrm{NF} \\
\mathrm{NF} \\
\mathrm{HT}, \mathrm{DM} \\
\mathrm{NF} \\
\mathrm{NF} \\
\text { Uterine fibroid } \\
\mathrm{NF} \\
\mathrm{NF} \\
\mathrm{NF}\end{array}$ & $\begin{array}{l}\mathrm{N} \\
\mathrm{N} \\
\mathrm{N} \\
\mathrm{N} \\
\mathrm{N} \\
\mathrm{N} \\
\mathrm{N} \\
\mathrm{N} \\
\mathrm{N}\end{array}$ \\
\hline
\end{tabular}

Abbreviations $\square \mathrm{F}$, female; $M$, male; ALF, acute liver failure; SALF, subacute liver failure; NF, not found; HT, hypertension; DM, diabetes mellitus; N, no

Table 2. Features of hemophagocytic lymphohistiocytosis in the context of liver failure 


\begin{tabular}{|c|c|c|c|c|c|c|c|c|c|}
\hline \multirow{2}{*}{$\begin{array}{l}\text { Is at diagnosis } \\
\text { LH }\end{array}$} & \multicolumn{7}{|c|}{ Patients } & \multirow[b]{2}{*}{8} & \multirow[b]{2}{*}{9} \\
\hline & 1 & 2 & 3 & 4 & 5 & 6 & 7 & & \\
\hline I items fulfilled & 7 & 7 & 7 & 7 & 8 & 7 & 8 & 7 & 6 \\
\hline current fever & Y & $\mathrm{Y}$ & $\mathrm{Y}$ & $\mathrm{Y}$ & $\mathrm{Y}$ & Y & $\mathrm{Y}$ & Y & $\mathrm{Y}$ \\
\hline slenomegaly & Y & Y & $\mathrm{Y}$ & $\mathrm{Y}$ & Y & $\mathrm{Y}$ & $\mathrm{Y}$ & $\mathrm{Y}$ & $\mathrm{N}$ \\
\hline əmophagocytosis & $\mathrm{N}$ & $\mathrm{Y}$ & $\mathrm{Y}$ & $\mathrm{Y}$ & $\mathrm{Y}$ & $\mathrm{Y}$ & $\mathrm{Y}$ & $\mathrm{Y}$ & $\mathrm{Y}$ \\
\hline ıncytopenia & $\mathrm{N}$ & $\mathrm{N}$ & $\mathrm{Y}$ & $\mathrm{Y}$ & $\mathrm{Y}$ & $\mathrm{N}$ & $\mathrm{Y}$ & $\mathrm{N}$ & $\mathrm{N}$ \\
\hline cytopenia & $\mathrm{Y}$ & $\mathrm{Y}$ & $\mathrm{N}$ & $\mathrm{N}$ & $\mathrm{N}$ & $\mathrm{Y}$ & $\mathrm{N}$ & $\mathrm{N}$ & $\mathrm{Y}$ \\
\hline rritin (ng/mL) & 2077 & 10468 & 736 & 144.7 & 1533.4 & 825 & 3379 & 15000 & 41223 \\
\hline K activity (\%) & 14.57 & 20.12 & 17.87 & 10.05 & 12.08 & 16.27 & 13.74 & 13.60 & 16.17 \\
\hline :D25 (pg/mL) & 14219 & 35017 & 10168 & 8140 & 25817 & 10186 & 11389 & 11934 & 20714 \\
\hline 3 (mmol/L) & 5.51 & 3.64 & 1.35 & 4.5 & 3.6 & 2.15 & 3.01 & 6.45 & 3.46 \\
\hline brinogen (g/L) & 0.94 & 0.83 & 0.99 & 1.44 & 0.64 & 0.78 & 1.36 & 1.49 & 1.95 \\
\hline J $\left(\times 10^{9} / \mathrm{L}\right)$ & 3.09 & 2.93 & 1.65 & 0.5 & 1.88 & 2.76 & 1.04 & 9.08 & 13.95 \\
\hline $\mathrm{J}\left(\times 10^{9} / \mathrm{L}\right)$ & 2.17 & 1.2 & 0.7 & 0.27 & 0.77 & 2.51 & 0.5 & 7.1 & 12.43 \\
\hline $1\left(\times 10^{9} / \mathrm{L}\right)$ & 0.36 & 1.1 & 0.42 & 0.15 & 1.04 & 0.51 & 0.4 & 0.51 & 0.75 \\
\hline $3(\mathrm{~g} / \mathrm{L})$ & $\begin{array}{l}56 \\
64\end{array}$ & $\begin{array}{l}79 \\
17\end{array}$ & $\begin{array}{l}87 \\
16\end{array}$ & $\begin{array}{l}74 \\
77\end{array}$ & $\begin{array}{l}60 \\
42\end{array}$ & $\begin{array}{l}67 \\
36\end{array}$ & $\begin{array}{l}75 \\
83\end{array}$ & $\begin{array}{l}127 \\
88\end{array}$ & $\begin{array}{l}99 \\
25\end{array}$ \\
\hline$(\mathrm{U} / \mathrm{L})$ & 87 & 617 & 20 & 218 & 168 & 27 & 272 & 474 & 384 \\
\hline (U/L) & 96 & 1111 & 40 & 85 & 53 & 54 & 386 & 789 & 688 \\
\hline (umo/L) & 199 & 827 & 171 & 739 & 340 & 233 & 602 & 280 & 339 \\
\hline $\mathrm{L}(\mathrm{umol} / \mathrm{L})$ & 107 & 626 & 101 & 353 & 233 & 140.9 & 434 & 181 & 123 \\
\hline$(\mathrm{U} / \mathrm{L})$ & 304 & 166 & 99 & 193 & 153 & 210 & 137 & 142 & 155 \\
\hline 3T (U/L) & 299 & 55 & 173 & 160 & 275 & 354 & 197 & 506 & 111 \\
\hline $\operatorname{lmin}(\mathrm{g} / \mathrm{L})$ & 37.5 & 33.6 & 33.1 & 29.7 & 29.8 & 34.0 & 31.2 & 27.1 & 24.3 \\
\hline $\mathrm{I}(\mathrm{U} / \mathrm{L})$ & 679 & 1124 & 240 & 218 & 380 & 249 & 264 & 1153 & 736 \\
\hline MG (mg/L) & 3.64 & 6.09 & 3.5 & 3.42 & 3.43 & 3.02 & 1.69 & 7.03 & 4.42 \\
\hline shadenopathy & & & $\mathrm{Y}$ & $\mathrm{N}$ & $\mathrm{Y}$ & $\mathrm{Y}$ & $\mathrm{Y}$ & $\mathrm{Y}$ & $\mathrm{Y}$ \\
\hline & & $\mathrm{N}$ & $\mathrm{N}$ & $\mathrm{N}$ & $\mathrm{Y}$ & $\mathrm{N}$ & $\mathrm{Y}$ & $\mathrm{Y}$ & $\mathrm{N}$ \\
\hline lromal & Fever & Fever & Jaundice & Fever & Fever & Fever & Fever & Fever & Fever \\
\hline logy & NA & NA & NA & NA & NA & NA & NA & NA & AOSD \\
\hline
\end{tabular}

Abbreviations: NK $\square$ nature killer; TG, triacylglycerol; WBC, white blood cells; HGB, hemoglobin; PLT, platelet; ALT, alanine aminotransferase; AST, aspartate aminotransferase; TBIL, total bilirubin; DBIL, direct bilirubin; ALP, alkaline phosphatase; GGT, glutamyl transpeptidase; LDH, lactic dehydrogenase; MG, macroglobulin. Reference range: WBC: 3.5-9.5 × 10^9/L, HGB: 130$175 \mathrm{~g} / \mathrm{L} ; \mathrm{PLT}: 125-350 \times 109 / \mathrm{L} ; \mathrm{ALT}: 7-40 \mathrm{u} / \mathrm{L} ; \mathrm{AST}, 9-50 \mathrm{u} / \mathrm{L}(\mathrm{M}) ;$ AST: 13-35 U/L (F), 15-40 U/L

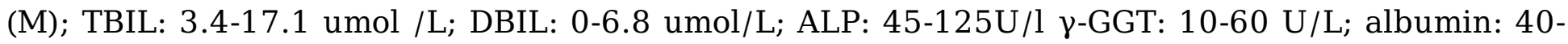

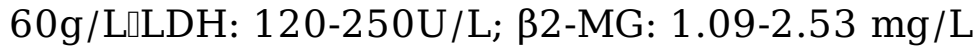

Table 3. Response rate and changes in evaluation indicators before and after treatment of different course of modified DEP regimen. 


\begin{tabular}{|c|c|c|c|c|c|}
\hline & $\begin{array}{c}\text { Diagnose-HLH } \\
(n=9)\end{array}$ & 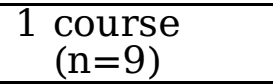 & $\begin{array}{c}2 \text { courses } \\
(\mathrm{n}=8)\end{array}$ & $\begin{array}{l}3 \text { courses } \\
(\mathrm{n}=6)\end{array}$ & $\begin{array}{c}4 \text { courses } \\
(n=6)\end{array}$ \\
\hline $3 \mathrm{C}\left(\times 10^{9} / \mathrm{L}\right)$ & $4.1 \pm 4.5$ & $6.1 \pm 6.3$ & $6.9 \pm 4.4$ & $5.2 \pm 1.7$ & $9.2 \pm 5.5$ \\
\hline ralue & & & & & $0.08^{\mathrm{a}}$ \\
\hline $\begin{array}{l}\text { iB (g/L) } \\
\text { alue }\end{array}$ & $80.4 \pm 21.9$ & $83.7 \pm 13.6$ & $84.8 \pm 18.0$ & $92.8 \pm 16.0$ & $\begin{array}{l}115.8 \pm 14.1 \\
0.08^{\mathrm{a}}\end{array}$ \\
\hline $\begin{array}{l}\mathrm{T}\left(\times 10^{9} / \mathrm{L}\right) \\
\text { ralue }\end{array}$ & $49.8 \pm 29.7$ & $\begin{array}{l}157.2 \pm 118.1 \\
0.021^{b}\end{array}$ & $\begin{array}{l}181.4 \pm 85.6 \\
0.012^{\mathrm{c}}\end{array}$ & $152.00 \pm 85.9$ & $197.6 \pm 78.7$ \\
\hline $\begin{array}{l}\text { T (U/L) } \\
\text { ralue }\end{array}$ & $251.9 \pm 206.2$ & $\begin{array}{l}111.1 \pm 106.5 \\
0.066^{b}\end{array}$ & $\begin{array}{l}47.6 \pm 46.3 \\
0.025^{c}\end{array}$ & $\begin{array}{l}44.2 \pm 24.4 \\
0.028\end{array}$ & $25.8 \pm 11.7$ \\
\hline $\begin{array}{l}\mathrm{T}(\mathrm{U} / \mathrm{L}) \\
\text { alue }\end{array}$ & $367.0 \pm 401.7$ & $\begin{array}{l}81.3 \pm 74.6 \\
0.008^{b}\end{array}$ & $\begin{array}{l}33.5 \pm 27.2 \\
0.012^{\mathrm{c}}\end{array}$ & $\begin{array}{l}36.9 \pm 11.2 \\
0.012^{\mathrm{d}}\end{array}$ & $22.8 \pm 8.1$ \\
\hline $\begin{array}{l}\text { IL (umo/L) } \\
\text { alue }\end{array}$ & $414.4 \pm 244.6$ & $\begin{array}{l}167.4 \pm 134.2 \\
0.008^{b}\end{array}$ & $\begin{array}{l}63.3 \pm 47.9 \\
0.012^{c}\end{array}$ & $\begin{array}{l}25.2 \pm 16.4 \\
0.012^{d}\end{array}$ & $15.2 \pm 13.8$ \\
\hline $\begin{array}{l}\text { IL (umol/L) } \\
\text { ralue }\end{array}$ & $255.4 \pm 180.7$ & $\begin{array}{l}95.3 \pm 92.0 \\
0.008^{b}\end{array}$ & $\begin{array}{l}28.7 \pm 25.4 \\
0.012^{\mathrm{c}}\end{array}$ & $\begin{array}{l}9.8 \pm 8.9 \\
0.028^{d}\end{array}$ & $3.3 \pm 3.1$ \\
\hline $\begin{array}{l}\mathrm{P}(\mathrm{U} / \mathrm{L}) \\
\text { alue }\end{array}$ & $173.2 \pm 58.6$ & $175.9 \pm 105.6$ & $138.8 \pm 84.9$ & $142.2 \pm 96.3$ & $\begin{array}{l}113.2 \pm 72.9 \\
0.24 \mathrm{e}^{\mathrm{a}}\end{array}$ \\
\hline $\begin{array}{l}\text { jGT (U/L) } \\
\text { alue }\end{array}$ & $236.7 \pm 136.8$ & $200.0 \pm 93.2$ & $204.1 \pm 139.7$ & $176.7 \pm 140.4$ & $\begin{array}{l}79.4 \pm 58.3 \\
0.019 \mathrm{e}^{\mathrm{e}}\end{array}$ \\
\hline $\begin{array}{l}\text { Jumin }(g / L) \\
\text { alue }\end{array}$ & $31.1 \pm 4.0$ & $31.4 \pm 3.7$ & $\begin{array}{l}40.1 \pm 3.8 \\
0.012^{c}\end{array}$ & $37.5 \pm 6.5$ & $37.7 \pm 4.1$ \\
\hline $\begin{array}{l}\mathrm{H}(\mathrm{U} / \mathrm{L}) \\
\text { alue }\end{array}$ & $560.3 \pm 379.3$ & $\begin{array}{l}397.0 \pm 210.5 \\
0.036^{d}\end{array}$ & $\begin{array}{l}278.1 \pm 85.9 \\
0.025^{\mathrm{c}}\end{array}$ & $\begin{array}{l}447.1 \pm 268.8 \\
0.075^{f}\end{array}$ & $\begin{array}{l}207.8 \pm 43.9 \\
0.043^{\mathrm{e}}\end{array}$ \\
\hline $\begin{array}{l}\text { rritin }(\mathrm{ng} / \mathrm{mL}) \\
\text { alue }\end{array}$ & $8736 \pm 13331$ & $\begin{array}{l}3022 \pm 3112 \\
0.05^{b}\end{array}$ & $1982 \pm 3898$ & $10780 \pm 22725$ & $\begin{array}{l}1377 \pm 2831 \\
0.043^{\mathrm{e}}\end{array}$ \\
\hline $\begin{array}{l}\text { D25 (pg/mL) } \\
\text { alue }\end{array}$ & $16398 \pm 9010$ & $\begin{array}{l}4272 \pm 3202 \\
0.008^{b}\end{array}$ & $2627 \pm 3102$ & $2174 \pm 2176$ & $2211 \pm 2293$ \\
\hline $\begin{array}{l}(\mathrm{mmol} / \mathrm{L}) \\
\text { ralue }\end{array}$ & $3.74 \pm 1.58$ & $\begin{array}{l}2.54 \pm 1.13 \\
0.093 \mathrm{~b}\end{array}$ & $\begin{array}{l}1.61 \pm 0.74 \\
0.012^{c}\end{array}$ & $\begin{array}{l}1.19 \pm 0.29 \\
0.028^{f}\end{array}$ & $\begin{array}{l}1.89 \pm 0.63 \\
0.043^{\mathrm{e}}\end{array}$ \\
\hline $\begin{array}{l}\text { rinogen }(\mathrm{g} / \mathrm{L}) \\
\text { alue }\end{array}$ & $0.98 \pm 0.38$ & $\begin{array}{l}1.27 \pm 0.25 \\
0.038^{b}\end{array}$ & $\begin{array}{l}1.70 \pm 0.56 \\
0.017^{\mathrm{c}}\end{array}$ & $1.74 \pm 0.95$ & $2.85 \pm 0.75$ \\
\hline $\begin{array}{l}\text { sponse rate } \\
\mathrm{R}, \mathrm{n}(\%) \\
\mathrm{R}, \mathrm{n}(\%)\end{array}$ & & $\begin{array}{l}0 \\
9(100 \%)\end{array}$ & $\begin{array}{l}1(12.5 \%) \\
7(87.5 \%)\end{array}$ & $\begin{array}{l}4(66.7 \%) \\
2(33.3 \%)\end{array}$ & $\begin{array}{l}5(83.3 \%) \\
1(16.7 \%)\end{array}$ \\
\hline
\end{tabular}

a: HLH vs. 4 courses; b: HLH vs. 1 course; c: HLH vs. 2 courses; d: 1 course vs. 2 courses; e: HLH vs. 4 courses; f: HLH vs. 3 courses; Abbreviations: WBC, white blood cells; HGB, hemoglobin; PLT, platelet; ALT, alanine aminotransferase; AST, aspartate aminotransferase; TBIL, total bilirubin; DBIL, direct bilirubin; ALP, alkaline phosphatase; GGT, glutamyl transpeptidase; LDH, lactic dehydrogenase; TG, triacylglycerol.

\section{Figures}




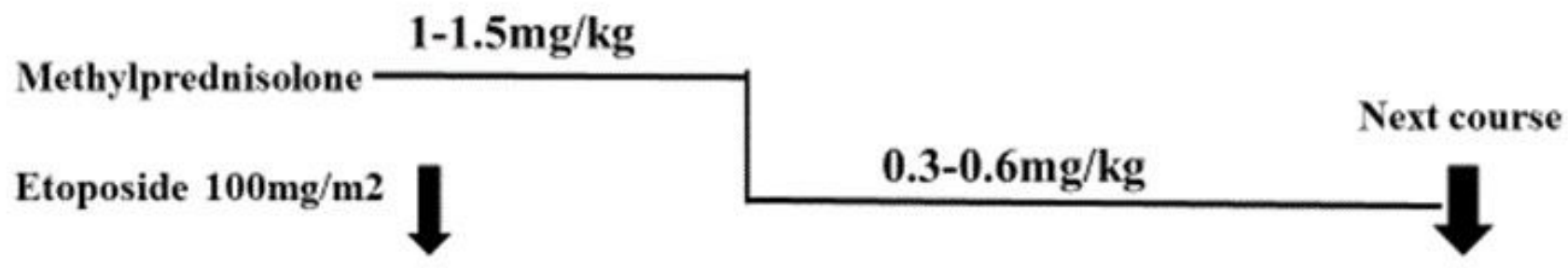

\section{Liposomal doxorubicin}

$15-25 \mathrm{mg} / \mathrm{m} 2$

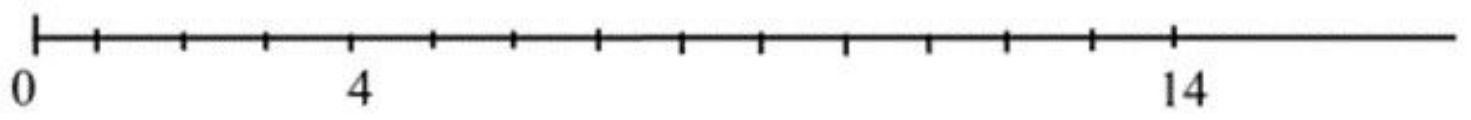

Figure 1

Dosage of modified DEP regimen. The horizontal axis of this figure is a timeline, split into days 
A

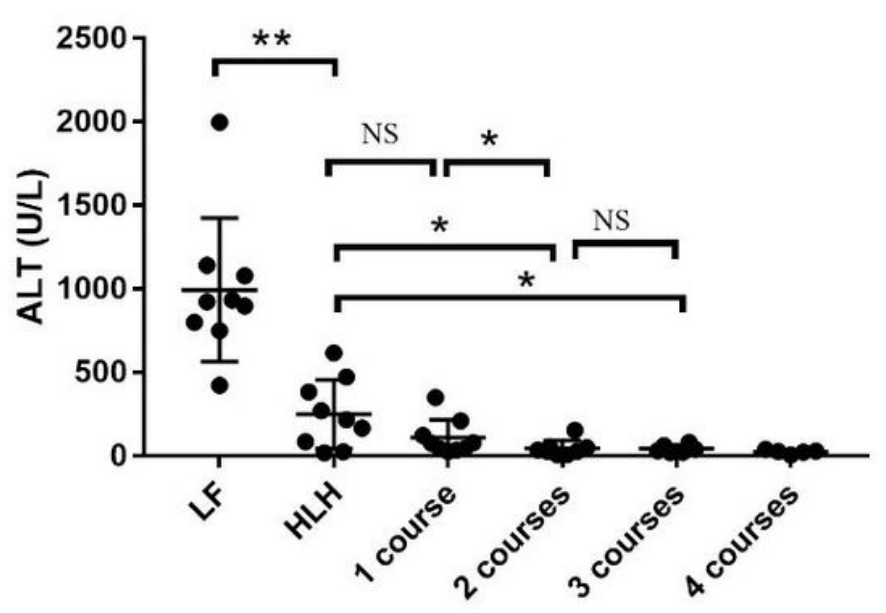

Different stage

C

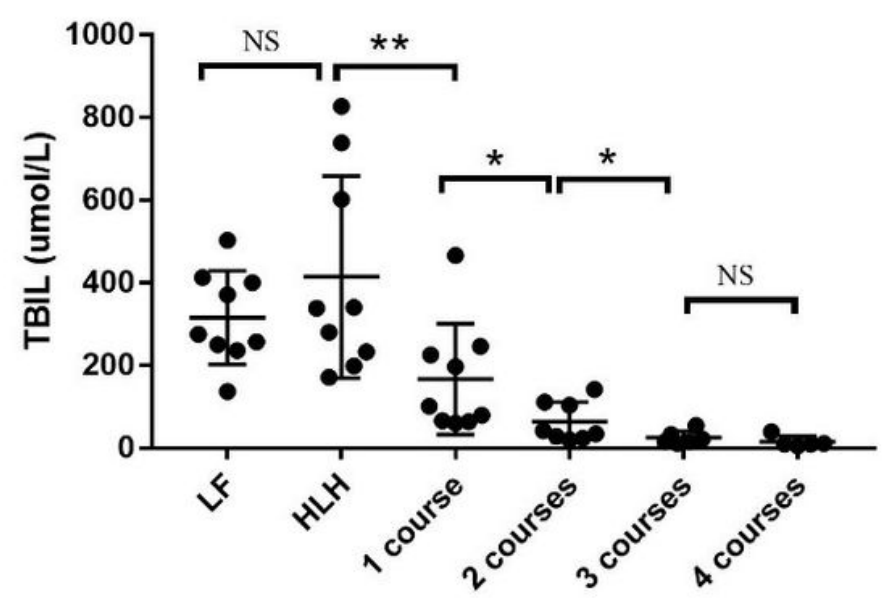

Different stage
B

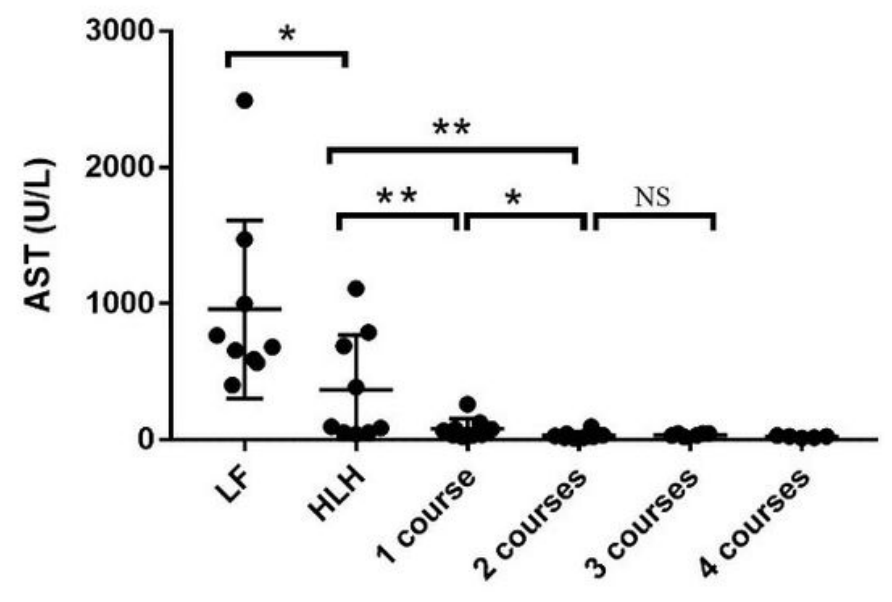

Different stage

D

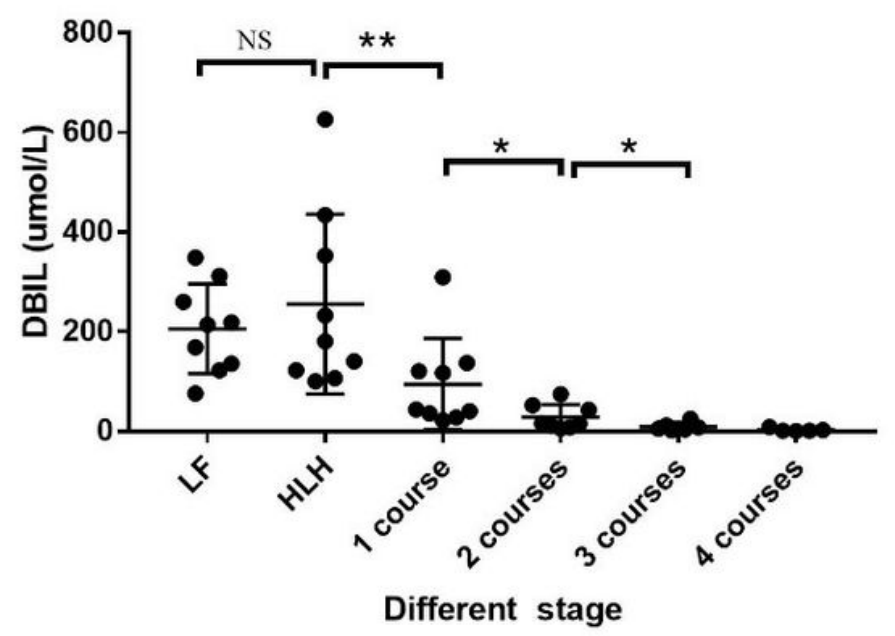

Figure 2

Changes of biotransformation function of liver at different stage of $\mathrm{HLH}$, patients diagnosed with liver failure (LF), hemophagocytic lymphohistiocytosis (HLH) and after different course of modified DEP regimen. * $\mathrm{P}<0.05$, ** $\mathrm{P}<0.01$ 